\title{
Dying with Dementia: a Challenge for Palliative Care Now and in the Future
}

\author{
Morrer com Demência: um Desafio para os Cuidados Paliativos Agora e \\ no Futuro
}

Ana CARDOSO ${ }^{1}$, David JOLLEY ${ }^{2,3}$, Ann REGAN ${ }^{1}$, Michael TAPLEY ${ }^{1}$

Acta Med Port 2014 Jul-Aug;27(4):414-416

Keywords: Dementia; Continuity of Patient Care; Community Health Service; Terminal Care; Palliative Care; Aged; England.

Palavras-chave: Demência; Continuidade de Cuidados ao Doente; Serviço de Saúde Comunitário; Cuidados Terminais; Cuidados

Paliativos; Idoso; Inglaterra.

Dementia is identified as the most significant health problem in the world because of its prevalence and impact on individuals, families and economies. It affects nearly 36 million people now and the number will double by $2030 .{ }^{1}$

Palliative care, with its previous emphasis on care for patients with cancer, is increasingly reaching out to help a wider community of the dying, including those dying with dementia. $^{2}$

Dementia has a similar prevalence in Portugal as in the UK and it may be appropriate to explore how people with dementia can access dementia care, especially towards the end of life, wherever they are living, whether at home, in hospital or in the nursing home.

Although there are differences in healthcare provision between the two countries, many of the principles of patient centred care in dementia may well be universally applicable as a guide to good practice.

\section{Background}

The modern hospice movement traces its origins to the pioneering work of Cicely Saunders in London. Her mission was to bring relief from pain to people dying from cancer or related conditions and the early history of hospices has been strongly linked to cancer. ${ }^{3}$

It has become clear that the palliative approaches to incurable, progressive, distressing conditions exemplified by cancer, can be extended with benefit to a range of other conditions. These include neurological disorders, muscular dystrophies, heart failure, respiratory failure, diabetes and more. $^{4}$

This approach, with its roots in the UK, is now applied in many countries around the world, including Portugal.

\section{Current and future needs of the dying}

Calanzani et al report to inform of the predictable need for specialist palliative care internationally over the next 10 15 years delivered interesting findings. Death is displaced to late life: $36 \%$ of those dying are aged 85 years or older, by
2035 the proportion will be $50 \%$. Most deaths in very late life are, and will be, due to cancer or to dementia. One in three people dying aged 65 and older die with dementia. ${ }^{4}$

Fifty percent of people aged $85+$ say that a specialist palliative care unit would be their preferred place to die, yet people in this age group, including those with dementia, are least likely to be admitted there at present. ${ }^{5}$

\section{Dementia}

Although dementia does occur amongst relatively young people it is strongly associated with later life. Once an individual has developed dementia it will stay with them until they die. It will contribute as a cause of death and modify the experience of dying even when other conditions such as cancer, heart disease or stroke are seen as the main terminal event. ${ }^{2}$

\section{The clinical syndrome of dementia}

Dementia derives from an underlying organic disorder of the brain. In most instances this is degenerative and progressive. Death may be a direct consequence of the degenerative condition which is characterised by progression of symptoms from memory impairment, often complicated by non-cognitive symptoms and behavioural change. From 'soft' physical signs such as dysphasia, dyspraxia and agnosia, to 'harder' symptoms including falls, incontinence, swallowing problems and inanition. The terminal phase of dementia may include immobility, contractures, decubitus ulcers, recurrent infections and may be associated with behaviour which appear to indicate distress and be unresponsive to most approaches to reassurance. ${ }^{6,7}$

\section{Death with dementia}

Some people with dementia die at home or during admission to hospital for other illnesses. Many others survive to die within care homes, nursing homes or other long-term care facilities. ${ }^{5}$

\footnotetext{
1. Willow Wood Hospice. Ashton under Lyne. United Kingdom.

2. Royal College of Psychiatrists. London. United Kingdom.

3. Personal Social Services Research Unit. University of Manchester. Manchester. United Kingdom.

Recebido: 15 de Abril de 2014 - Aceite: 25 de Agosto de 2014 | Copyright $\odot$ Ordem dos Médicos 2014
} 
The terminal phase of care for people with advanced dementia is often less than optimal as symptoms of distress may remain unresolved, sometimes with no appropriate attempt to ameliorate them. ${ }^{7}$

Pain may not be recognised because individuals cannot describe it but behave in a way which is puzzling or even frightening to observers. People with dementia with objectively painful conditions are less likely than others with the same condition to receive adequate analgesia. 'Behavioural problems' have been shown to be more greatly helped by analgesics than anti-psychotic medicines. ${ }^{8}$

Some patients are admitted repeatedly to acute hospital for assessment followed by ill-informed, inappropriate lifesustaining therapy which serves to prolong suffering, add to confusion and distress and may be associated with the development of additional complications such as decubitus ulcers, MRSA or other problems. ${ }^{9}$

\section{Where the problem starts}

Problems have been related to a failure to recognise dementia: less than half the predicted prevalence is known to family doctors or registered by them; and to failures of ownership or continuity of care: while death at home persists as the declared preferred outcome by many and adopted with little question by policymakers, the reality is that $60 \%$ of people with dementia have moved into care before dying. Transitions to such long-term, terminal placements are often mediated via a period in acute hospital. Sadly this may result in the benefits of knowledge and mutual respect achieved by primary care over many years being lost in the relocation to another place and into the hands of new medical and nursing staff. ${ }^{7,9}$

\section{Palliative Care and Dementia}

Interest in developing palliative care services for people in the end stages of dementia is growing. ${ }^{10}$ Most published reports relate to work in the USA and UK: a review of 200 papers yielded by a Medline search to Hospice AND Dementia from August 2006 - June 2014 included only 23 from other countries: France (8 reports); Germany (4); Canada (4); Japan (2); Holland (2); and Israel, China and Spain with one each.

Where palliative care services for people with dementia have been established they result in improvements in care, greater confidence and satisfaction amongst relatives and represent better use of resources; but, which models are most effective and most cost effective is not certain. ${ }^{10}$

\section{Models of care - an example}

We have been most impressed with the St Christopher's initiative led by Victor Pace which demonstrated that a small and inexpensive service could produce disproportionately effective benefits. A small team is led by a Specialist Nurse in Dementia with palliative skills and supported by the rest of the Palliative Care team, including physicians and a psychiatrist. The team mainly gives advice but will see individuals where this will be helpful, in whatever location they are living. It is well recognised that a change in place of residence, especially into the acute hospital environment, can precipitate a decline in cognitive function in patients with dementia.

The Dementia Specialist Nurse helps support patients and families to remain in their home or care homes, without necessitating admission to inpatient units. St. Christopher's also provided education, training and advice in care homes, general hospitals and the community. ${ }^{11}$

\section{Our experience}

Willow Wood Hospice have adopted the essential elements learned from St. Christopher's and replicated and extended the findings in the North of England. Our rate of contact has been roughly 80 per annum, extending palliative approaches to many who are not yet near to death but encountering difficulties. For some patients and families, help preparing plans for future care has been all that has been required. We work in collaboration with other professionals in the delivery service; of education, training and support, caring for people with dementia in care homes, hospital and the community. ${ }^{12}$

\section{Reflection}

Palliative care must change to respond to the challenge of helping a wider community of the dying, including those dying with dementia. ${ }^{13}$

The inclusion of dementia in the portfolio of Palliative Care was pioneered in the USA. It is beginning to be explored in units such as ours in Ashton-under-Lyne, in the UK and there are reports from other parts of Europe. Within each country, the details of development will depend upon the context, the strengths, weaknesses and ambitions of existing providers; but everywhere the relevance of dementia to the profile of people dying is growing ever more significant.

We hope that this report of our experience and reflections from the UK will be of interest and encouragement to the Palliative Care movement in Portugal.

\section{CONFLICT OF INTERESTS}

The authors declare that they have no conflicts of interest.

\section{FUNDING SOURCES}

No funding sources were identified.

\section{REFERENCES}

1. World Health Organisation, Alzheimer's Disease International. Dementia: a Public Health Priority. Geneva: World Health Organisation; [accessed 2014 Apr 07]. Available from: http://whqlibdoc.who.int/ publications/2012/9789241564458 eng.pdf.

2. Department of Health. Dementia - A state of the nation report on dementia care and support in England. London: Department of Health; 
2013 [accessed 2014 Apr 07]. Available from: https://www.gov.uk/ government/uploads/system/uploads/attachment_data/file/262139/ Dementia.pdf.

3. The work of Cicely Saunders. London: Help the Hospices; 2014 [accessed 2014 Apr 07]. Available from: http://www.helpthehospices. org.uk/about-hospice-care/what-is-hospice-care/hospice-history/thework-of-cicely-saunders/.

4. Calanzani N, Higginson I, Gomes B. Current and future needs for hospice care: an evidence-based report. London: Commission into the Future of Hospice care; 2013.

5. Perrels AJ, Fleming J, Zhao J, Barclay S, Farquhar M, Buiting HM, et al. Place of death and end-of-life transitions experienced by very old people with differing cognitive status: Retrospective analysis of a prospective population-based cohort aged 85 and over. Palliat Med. 2014;28:220 33.

6. Black D, Jolley D. Slow euthanasia? The deaths of psychogeriatric patients. BMJ. 1990;300:1321-23.

7. Hughes JC, Jolley D, Jordan A, Sampson EL. Palliative care in dementia: issues and evidence. Adv Psychiatr Treat. 2007;13:251-60.
8. Husebo BS, Ballard C, Cohen-Mansfield J, Seifert R, Aarsland D. The response of agitated behavior to pain management in persons with dementia. Am J Geriatr Psychiatry. 2014;22:708-17.

9. Alzheimer's Society. Counting the cost: caring for people with dementia on hospital wards. London: Alzheimer's Society; 2009. [accessed 2014 Apr 07]. Available from: http://www.alzheimers.org.uk/site/scripts/ download.php?filelD=787

10. Volicer L, Collard A, Hurley A, Bishop C, Kern D, Karon S. Impact of special care unit for patients with advanced Alzheimer's disease on patients' discomforts and costs. J Am Geriatr Soc. 1994;42:597-603.

11. Scott S, Pace V. The first fifty patients: a brief report on the initial findings from the Palliative care in dementia project. Dementia. 2009;8:435-41.

12. Tapley M, Regan A, Jolley D. Hospice: putting the heart back into dementia care. Journal of Dementia Care. 2013;21:14-5.

13. van der Steen JT, Radbruch L, Hertogh CM, de Boer ME, Hughes JC, Larkin $\mathrm{P}$, et al. White paper defining optimal palliative care in older people with dementia: a Delphi study and recommendations from the European Association for Palliative Care. Palliat Med. 2014;28:197-209. 


\section{Dying with Dementia: a Challenge for Palliative Care Now and in the Future \\ Acta Med Port 2014:27:414-416}

Publicado pela Acta Médica Portuguesa, a Revista Científica da Ordem dos Médicos

Av. Almirante Gago Coutinho, 151

1749-084 Lisboa, Portugal.

Tel: +351218428215

E-mail: submissao@actamedicaportuguesa.com

www.actamedicaportuguesa.com

ISSN:0870-399X | e-ISSN: 1646-0758

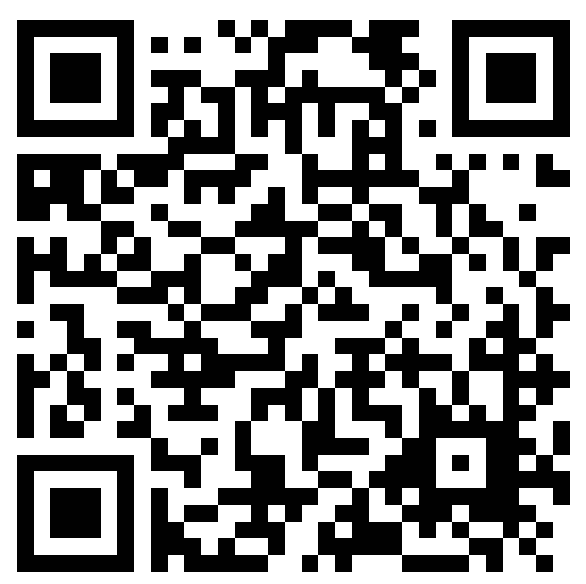

